\title{
Los biocombustibles y su efecto en la agricultura peruana
}

\author{
Mg. Pedro Barrientos Felipa*
}

\section{Metodología}

Nuestra investigación es del tipo cualitativa, ya que recurriremos a la recolección de datos y entrevistas personales para conocer la situación y desarrollo del mercado de los biocombustibles. Aplicamos el tipo de investigación exploratoria, siendo nuestra fuente primaria entrevistas a personas especializadas en el tema, teniendo en cuenta su preparación y experiencia, como por ejemplo representantes capacitados de organismos $e$ instituciones públicas y privadas que están comprometidas con el desarrollo de los biocombustibles en el Perú. En cuanto a información secundaria, esta se obtuvo de los principales organismos locales y extranjeros relacionados al tema, en relación a la producción de biocombustibles en el Perú.

* Economista por la Universidad Ricardo Palma. Magíster en Administración por la Universidad del Pacífico. Profesor Asociado por la Universidad Nacional Mayor de San Marcos. Miembro del Instituto de Investigaciones Económicas. Su campo de investigación es la agroexportación. 


\section{Pedro Barrientos Felipa}

\section{INTRODUCCIÓN}

En las últimas décadas el proceso de desarrollo económico del mundo, en especial de los países industrializados, ha hecho que la necesidad de consumir energía se haya incrementado y que la actual producción de petróleo no sea suficiente para abastecer la demanda de energía. Estudios europeos estiman que el consumo mundial de petróleo, combinando factor demográfico con una tasa anual de crecimiento de la economía mundial de 3.5\% durante las próximas dos décadas, deberá pasar de 9.3 mil millones de toneladas a 15 mil millones $(2020)^{1}$. Dada esta situación a futuro, las reservas estimadas y la producción actual de la $\mathrm{OPEP}^{2}$, solo se podrá cubrir el $50 \%$ de esta demanda; es así que se muestra a los combustibles de origen orgánico, es decir los biocombustibles, como una propuesta innovadora en la sustitución y diversificación de las fuentes energéticas actuales.

La palabra biocombustibles de repente ha invadido las crónicas de los diferentes tipos de comunicación, con la clara idea de que estos son parte de la solución a un futuro en el cual la oferta de petróleo cada vez disminuye. Pero, ¿qué son los biocombustibles? El concepto no es tan limitado como aparentemente pareciera, sino que es más amplio. La etimología de la palabra sería un combustible de origen biológico. Así tal cual, incluso el petróleo lo sería, pues procede de restos fósiles de seres que vivieron hace millones de años. Pero se tiende a definir como biocombustible a un combustible de origen biológico obtenido de materia renovable a partir de restos orgánicos. Esta fue la primera fuente de energía que conoció la humanidad. Y es sobre este tipo de energía que trata la investigación y cuyos resultados exponemos en este artículo.

Una de sus otras definiciones es que se le considera como un conjunto heterogéneo de productos orgánicos cuya característica común es la de haber tenido un origen biológico en su pasado inmediato. Es posible utilizar este tipo de combustible como complemento o para aprovechar ciertos recursos que sería de todos modos desperdicia-

1 Diario Gestión (18 de setiembre de 2007).

2 OPEP. Organización de Países Productores de Petróleo. Organization of the petroleum exporting countries, OPEC's mission is to coordinate and unify the petroleum policies of Member Countries and ensure the stabilization of oil markets in order to secure an efficient, economic and regular supply of petroleum to consumers, a steady income to producers and a fair return on capital to those investing in the petroleum industry. 


\section{Los biocombustibles y su efecto en la agricultura peruana}

dos. Aunque cubra un pequeño porcentaje de la producción de energía total aportaría su contribución de todos modos. En realidad toda sustancia susceptible de ser oxidada produce energía. Si esta sustancia procede de plantas, entonces al ser quemada (oxidada) devuelve a la atmósfera el dióxido de carbono que la planta tomó del aire tiempo atrás. Por tanto, desde el punto de vista ecológico es un sistema que respeta el medio ambiente, pues no hay un aumento neto de gases de efecto invernadero.

El uso de biocombustibles tiene impactos ambientales negativos y positivos. Los impactos negativos hacen que, a pesar de ser una energía renovable, no sea considerado por muchos expertos como una energía no contaminante y, en consecuencia, tampoco una energía verde.

Una de las causas es que, pese a que en las primeras producciones de biocombustibles solo se utilizaban los restos de otras actividades agrícolas, con su generalización y fomento en los países desarrollados, muchos países subdesarrollados, especialmente del sureste asiático, están destruyendo sus espacios naturales, incluyendo selvas y bosques, para crear plantaciones para biocombustibles. La consecuencia de esto es justo la contraria de lo que se desea conseguir con los biocombustibles: los bosques y selvas limpian más el aire de lo que lo hacen los cultivos que se ponen en su lugar.

Algunas fuentes afirman que el balance neto de emisiones de dióxido de carbono por el uso de biocombustibles es nulo debido a que la planta, mediante fotosíntesis, captura durante su crecimiento el $\mathrm{CO}_{2}$ que será emitido en la combustión del biocombustible. Sin embargo, muchas operaciones realizadas para la producción de biocombustibles, como el uso de maquinaria agrícola, la fertilización o el transporte de productos y materias primas, actualmente utilizan combustibles fósiles y, en consecuencia, el balance neto de emisiones de dióxido de carbono es positivo.

Otras de las causas del impacto ambiental son las debidas a la utilización de fertilizantes y agua necesarios para los cultivos; el transporte de la biomasa; el procesado del combustible y la distribución del biocombustible hasta el consumidor. Varios tipos de fertilizantes tienden a degradar los suelos al acidificarlos. El consumo de agua para el cultivo supone disminuir los volúmenes de las reservas y los caudales de los cauces de agua dulce. 


\section{Pedro Barrientos Felipa}

Algunos procesos de producción de biocombustible son más eficientes que otros en cuanto al consumo de recursos y a la contaminación ambiental. Por ejemplo, el cultivo de la caña de azúcar requiere el uso de menos fertilizantes que el cultivo del maíz, por lo que el ciclo de vida del bioetanol de caña de azúcar supone una mayor reducción de emisiones de gases de efecto invernadero respecto al ciclo de vida de combustibles fósiles con más efectividad que el ciclo del bioetanol derivado del maíz. Sin embargo, aplicando las técnicas agrícolas y las estrategias de procesamiento apropiadas, los biocombustibles pueden ofrecer ahorros en las emisiones de al menos el 50\%, comparando con combustibles fósiles como el gasóleo o la gasolina.

El uso de biocombustibles de origen vegetal produce menos emisiones nocivas de azufre por unidad de energía que el uso de productos derivados del petróleo. Debido al uso de fertilizantes nitrogenados, en determinadas condiciones el uso de biocombustibles de origen vegetal puede producir más emisiones de óxidos de nitrógeno que el uso de productos derivados del petróleo. La tendencia a nivel mundial de la producción de este biocombustible en los últimos años muestra una tendencia creciente, reflejando la distribución de la producción hacia sus principales usos, especialmente en el uso de combustible. Dentro de este marco, los biocombustibles líquidos (o biocarburantes), obtenidos a partir de materias primas de origen agrícola, son productos que están siendo utilizados a nivel comercial como sustitutos de los combustibles derivados de petróleo. Así tenemos ${ }^{3}$ :

- El biodiesel. Obtenido a partir de aceites provenientes de semillas oleaginosas (girasol, colza o canola, soja, coco, etc.), de frutos oleaginosos (palma y otros), de aceites vegetales de deshecho (aceite de fritura usados) o grasas animales. Los aceites o grasas deben pasar por un proceso denominado transesterificación, para obtener el biodiesel. El procedimiento se inicia calentando el aceite, para luego mezclarlo con las cantidades adecuadas de alcohol metílico y un elemento catalizador, posteriormente es lavado con agua acidificada. Finalmente, se obtiene el biodiesel y como subproducto se tendrá el glicerol (glicerina). Este producto final estará listo para ser incorporado al combustible diesel común.

3 Informe quincenal de la Sociedad Nacional de Minería, Petróleo y Energía. 32 - Julio 2006 


\section{Los biocombustibles y su efecto en la agricultura peruana}

- El bioetanol. Obtenido a partir del alcohol proveniente de distintas plantas como la caña de azúcar, la remolacha, maíz, residuos forestales y otros. El producto se obtiene por la fermentación de plantas, que dan lugar a un alcohol etílico. Este producto debe además ser sometido a un proceso que lo libere de agua; solo entonces el producto está listo para ser mezclado con la gasolina común que además de oxigenarla, permite aprovechar el alto nivel de octano que posee.

\section{Marco Legal y promoción desde el Estado}

El Perú cuenta con un marco legal específico para la promoción de los biocombustibles, conformado por:

- Ley N. ${ }^{\circ}$ 28054, Ley de Promoción del Mercado de Biocombustibles (agosto de 2003).

- D.S. N. ${ }^{\circ}$ 013-2005 - EM, Reglamento de la Ley de Promoción del Mercado de Biocombustibles (marzo de 2005).

- D.S. N. ${ }^{\circ} 021$ - 2007 - EM, Reglamento para la Comercialización de Biocombustibles (abril de 2007).

- Directiva N. ${ }^{\circ}$ 004-2007-PROINVERSIÓN, Lineamientos del Programa de Promoción del Uso de Biocombustibles - PROBIOCOM (marzo de 2007).

Para la elaboración de la propuesta de Ley se constituyó un Grupo Técnico de Biocombustibles (2002), liderado por el CONAM; el cual, en su informe técnico, presentó al biodiesel como una «oportunidad para reemplazar progresivamente parte de la importación de diésel, y reducir la contaminación ambiental, generando al mismo tiempo nuevas oportunidades de desarrollo agrícola y agroindustrial en el país», planteándolo principalmente en base a la promoción del cultivo de palma aceitera y soya.

La Ley N. ${ }^{\circ} 28054$ «establece el marco general para promover el desarrollo del mercado de los biocombustibles sobre la base de la libre competencia y el libre acceso a la actividad económica, con el objetivo de diversificar el mercado de combustibles, fomentar el desarrollo agropecuario y agroindustrial, generar empleo, disminuir la contaminación ambiental y ofrecer un mercado alternativo en la lucha contra las drogas». 


\section{Pedro Barrientos Felipa}

Aunque la ley trata de biocombustibles en general, se orienta específicamente a la promoción de los biocombustibles líquidos, específicamente al biodiesel y etanol. Entre sus políticas generales incluye: la generación de investigación; la formación de recursos humanos de alta especialización; el desarrollo de proyectos experimentales y la transferencia de tecnología; la participación privada para la producción; y el incentivo de la comercialización para utilizar los biocombustibles en todos los ámbitos de la economía, puros o mezclados con otro combustible.

\section{Etanol}

El Bioetanol es lo mismo que el Etanol. El Etanol es el alcohol etílico producido a partir de la fermentación de los azúcares que se encuentran en los productos vegetales (cereales, caña de azúcar, remolacha o biomasa) combinados en forma de sacarosa, almidón, hemicelulosa y celulosa. Dependiendo de su fuente de obtención, su producción implica fundamentalmente el proceso de separación de las azúcares, y la fermentación y destilación de las mismas. El etanol tiene como ventajas:

Se produce a partir de fuentes renovables.

- Presenta un elevado índice de octanaje (105), favoreciendo la combustión y evitando el golpeteo.

- Produce menos dióxido de carbono que la gasolina, aunque el impacto total depende de los procesos de destilación y la eficiencia de los cultivos.

- Genera menos monóxidos de carbono al utilizarse como aditivo en la gasolina. Con el uso de $10 \%$ de etanol en la mezcla se puede lograr un reducción de $25 \%$ a $30 \%$ en las emisiones de $\mathrm{CO}$.

- Es menos inflamable que la gasolina y el diesel.

- Baja toxicidad.

- No emite compuestos de azufre.

- La combinación de $90 \%$ de gasolina y $10 \%$ etanol puede ser usado en los vehículos sin ninguna modificación. 


\section{Los biocombustibles y su efecto en la agricultura peruana}

A nivel mundial, el etanol es usado principalmente como:

- Combustible. Ya sea para mezclar o reemplazar los usos del petróleo y derivados. El 65,4\% de producción mundial de etanol se usa como combustibles.

- Insumo en la industria procesadora. Dado que el $21 \%$ de la producción mundial se destina a las industrias de cosméticos, farmacéutica, química, entre otras.

- Insumo en la elaboración de bebidas. Utiliza alrededor del $13 \%$ de la producción mundial. Cabe destacar que la producción mundial de alcohol destinada al uso de combustibles se encuentra mayormente subsidiada. En el Perú, la producción de etanol se destina principalmente a la elaboración de bebidas, así como en la industria química y cosméticos.

Los subproductos generados ${ }^{4}$ en la producción de bioetanol, así como el volumen de los mismos, dependen en parte de la materia prima utilizada. En general, se pueden agrupar en dos tipos:

- Materiales lignocelulósicos: Tallos, bagazo, etc., correspondientes a las partes estructurales de la planta. En general, se utilizan para valorización energética en cogeneración, especialmente para cubrir las necesidades energéticas de la fase de destilación del bioetanol, aunque también se puede vender el excedente a la red eléctrica (con precio primado).

- Materiales alimenticios: Pulpa y granos de destilería de maíz desecados con solubles (DDGS), que son los restos energéticos de la planta después de la fermentación y destilación del bioetanol. Tienen interés para el mercado de piensos animales por su riqueza en proteína y valor energético.

La caña de azúcar es la planta más aprovechable por el bagazo generado para su combustión y generación energética. La remolacha azucarera genera, por su parte, unas 0.75 Ton de pulpa por tonelada de bioetanol producido.

4 http://www.miliarium.com/Monografias/Biocombustibles/Bioetanol/Bioetanol.asp (6 de octubre de 2008) 


\section{Pedro Barrientos Felipa}

Cuadro N. ${ }^{\circ}$ 1. Producción Mundial de Etanol 2001-2005 (Unidad de Medida: billones de litros)

\begin{tabular}{ccccc}
\hline \multirow{2}{*}{ Año } & \multirow{2}{*}{ Total } & \multicolumn{3}{c}{ Destino } \\
\cline { 3 - 5 } & & Combustible & Industria & Bebidas \\
\hline 2000 & 31.8 & 19.0 & 9.8 & 3.0 \\
2001 & 33.1 & 20.0 & 10.0 & 3.1 \\
2002 & 34.7 & 21.0 & 10.5 & 3.3 \\
2003 & 34.8 & 21.5 & 10.0 & 3.3 \\
2004 & 36.4 & 22.0 & 11.0 & 3.4 \\
2005 & 37.7 & 23.0 & 11.2 & 3.5 \\
\hline
\end{tabular}

Fuente: Proyecciones F. O. Licht

De acuerdo a las estadísticas internacionales (Cuadro 2), Brasil y Estados Unidos encabezan, respectivamente, la lista de principales países productores a nivel mundial, acumulando entre ellos un $64.2 \%$ de la producción mundial total; la cual ascendió en el año 2002 a 127, 871,529 litros de Etanol. Desde hace treinta años, Brasil ha desarrollado una extensa industria doméstica del etanol como combustible a partir de la producción y la refinación de la caña de azúcar. Brasil produce, aproximadamente, 15 millones de $\mathrm{m}^{3}$ de etanol por año. Brasil es considerado como la primera economía que logró un uso sostenible del etanol y el modelo a seguir por otros países. Comparado con el etanol producido en Estados Unidos con base en el maíz, la productividad del insumo energético en Brasil es ocho veces mayor que la estadounidense, y la productividad por hectárea es casi el doble, mientras en Estados Unidos se producen entre 3.800 a 4.000 litros de etanol por hectárea plantada de maíz, en Brasil se producen entre 6.800 a 8.000 litros por hectárea plantada de caña de azúcar 5 .

Estados Unidos es el mayor productor mundial de etanol, con 4,86 mil millones de galones líquidos producidos en el 2006; seguido por Brasil, con una producción de 4,49 mil millones de galones. EE.UU., junto con Brasil, destila el 70\% de la producción mundial de etanol; y en el 2007 produjeron el 88\% de etanol utilizado como combustible en el mundo. Casi la totalidad del etanol estadounidense es producido a partir de maíz, que es

5 Publicado por Wikipedia, teniendo como fuente Goettemoeller, Jeffrey; Adrian Goettemoeller (2007), Sustainable Ethanol: Biofuels, Biorefineries, Cellulosic Biomass, Flex-Fuel Vehicles, and Sustainable Farming for Energy Independence, Praire Oak Publishing, Maryville, Missouri, pp. 42 


\section{Los biocombustibles y su efecto en la agricultura peruana}

menos eficiente que el etanol producido a partir de caña de azúcar. Además, en el 2007, un $25 \%$ de la producción nacional de maíz fue desviada para producir etanol como combustible, lo que ha sido criticado y considerado como uno de los factores que influyeron en la crisis alimentaria de 2007 a 2008, cambiando alimentos por combustibles.

Cuadro N. ${ }^{\circ}$ 2. Producción Mundial de Etanol de los principales países productores - millones de galones, todos los grados de etanol

\begin{tabular}{lrrr}
\hline \multicolumn{1}{c}{ País } & $\mathbf{2 0 0 4}$ & $\mathbf{2 0 0 5}$ & $\mathbf{2 0 0 6}$ \\
\hline Brasil & 3,989 & 4,227 & 4,491 \\
Estados Unidos & 3,535 & 4.264 & 4,855 \\
China & 964 & 1,004 & 1,017 \\
India & 462 & 449 & 502 \\
Francia & 219 & 240 & 251 \\
Rusia & 198 & 198 & 171 \\
África del Sur & 110 & 103 & 102 \\
Reino Unido & 106 & 92 & 74 \\
Arabia Saudita & 79 & 32 & 52 \\
España & 79 & 93 & 122 \\
\multicolumn{1}{c}{$\quad$ Total } & $\mathbf{1 0 , 7 7 0}$ & $\mathbf{1 2 , 1 5 0}$ & $\mathbf{1 3 , 4 8 9}$ \\
\hline
\end{tabular}

Fuente: F. O. Licht

La demanda mundial de Etanol, como se menciono antes, está creciendo por el mayor uso que se le está dando a este biocombustible. Entre los principales demandantes o importadores se encuentran la Unión Europea y los Estados Unidos de Norteamérica, además de Brasil, el cual es uno de los mayores productores y consumidores de este biocombustible. Cabe mencionar que algunos países están siendo mayormente apoyados en el consumo de este biocombustible a través de medidas de los gobiernos para impulsar el consumo.

Así, las experiencias logradas en estos países han ocasionado que cada vez más se esté dando su uso en los países consumidores y en otros deseosos de experimentar una forma diferente de abastecerse energéticamente. Las importaciones de etanol en el año 2005 fueron de 51.5 miles de millones de galones, siendo los principales compradores la Unión Europea y los Estados Unidos de Norteamérica. 


\section{Pedro Barrientos Felipa}

El etanol está ganando mercado en reemplazo de la gasolina convencional y como oxigenante. Sin embargo, para tener éxito en estos mercados, el costo del etanol debe ser cercano al de la gasolina. En la Unión Europea el consumo aumento 6.5\% durante el 2006 y en el mercado norteamericano el consumo del etanol viene incrementándose tras ser requerido como reemplazo de la gasolina convencional. Además se proyecta que el consumo total de etanol alcanzaría los 12.9 miles de millones de galones en el 2016 (140\% más de lo observado actualmente).

\section{Etanol en el Perú}

En el 2003, la producción de alcohol rectificado ascendió a 30,4 millones de litros, creciendo ligeramente (2\%) en comparación al año anterior. El alcohol rectificado es un alcohol más puro que, generalmente, se obtiene en un segundo proceso de destilación. El Perú posee el mayor rendimiento a nivel mundial en la producción mundial de caña de azúcar ${ }^{6}$, siendo este un importante aliciente para producir etanol en base a la caña de azúcar, pese a ello no tenemos una elevada participación en la producción de caña, como el caso de Brasil, que fue el principal producto mundial. En Brasil, de las 360 mil toneladas de caña de azúcar producida, alrededor del $50 \%$ se destina a la elaboración de etanol y el otro 50\% restante a la producción de azúcar. Asimismo, el 80\% del etanol producido en Brasil se realiza en la misma instalación donde se produce azúcar. Es importante señalar que, en el Perú la mayor parte de la producción local de caña se destina a la elaboración de azúcar.

En el Perú, la producción de etanol se destina principalmente a la elaboración de bebidas. Las destilerías peruanas no elaboran alcohol anhidro etanol-combustible, cuya utilización es como carburante en la mezcla de gasolina con alcohol. Cabe destacar que con la actual capacidad de producción de las destilerías locales no se podría abastecer en el corto plazo la demanda externa de etanol, ante ello se requiere de nuevas inversiones para abastecer en el largo plazo el mercado exterior.

Las exportaciones de etanol sin desnaturalizar se realizaron de manera permanente a partir de 1999, como resultado del inicio de operaciones comerciales hacia el exterior

6 Fuente: Ministerio de Comercio Exterior y Turismo. "Perfil de Mercado y Competitividad exportadora del Etanol". 


\section{Los biocombustibles y su efecto en la agricultura peruana}

por parte del Complejo Agroindustrial Cartavio S.A. y Quimpac S.A. Entre el 2000 y el 2003, el valor de las exportaciones de etanol se expanden dinámicamente, tras crecer a una tasa promedio de $130 \%$ por año, ubicándose en US \$3,4 millones, reflejando el mayor interés de las empresas locales por atender el mercado exterior. En el 2002, el precio promedio de las exportaciones de etanol sin desnaturalizar alcanzó su mayor valor, tras ubicarse en US\$ 33 por litro; sin embargo, en el 2003, el precio promedio retrocedió a similares niveles registrados en años anteriores, al descender a US\$24 por litro.

Siguiendo los modelos donde el uso del etanol es obligatorio como mezcla de los combustibles carburantes, el desarrollo de la demanda para esta importante industria requerirá de un impulso legal que promueva una mayor incorporación de etanol en todas las gasolinas consumidas en el Perú. El Perú así como los otros países demandantes buscan reemplazar hasta cierto nivel, y en muchos casos combinar, el petróleo o gasolina con el etanol, lo cual generaría un ahorro en el nivel de precios de combustibles y obviamente una reducción considerable en la dependencia del petróleo como único combustible.

Según información brindada por parte de los entrevistados ${ }^{7}$, especialistas en este biocombustible, el Perú no sería en el corto plazo un consumidor de etanol como combustible, debido a las limitaciones del mercado interno para desarrollar e implementar esta industria. Es por ello que podemos tener oportunidades de elaborar un producto de demanda creciente en el exterior, siendo este un sector que no es clave en la gestión del estado, solo la empresa privada podrá desarrollar los proyectos de industrialización a escala del etanol. Aun sin cortar con el merecedor apoyo a este potencial producto, la empresa privada tiene enormes posibilidades de desarrollo en este sector.

En el Perú, uno de los insumos con mayor potencialidad para la producción de etanol es de la caña de azúcar. Sin embargo, es también productor de varios otros posibles insumos de manera satisfactoria y a su vez con altos rendimientos; entre los que destacan el maíz (almidones) y la celulosa; así como algunos otros cultivos nuevos cuyas alta rentabilidad y bajos costos están aún en discusión, como por ejemplo el sorgo, pero con un futuro prometedor para la industria del etanol. La caña de azúcar es la más ren-

table tomando en cuenta su menor costo de producción, mayor rendimiento por ha de cultivo y consumo medio de agua de riego. 


\section{Pedro Barrientos Felipa}

La producción mundial de caña de azúcar en el 2005 fue de 1267 millones t, siendo el principal productor Brasil con 34\% de la producción mundial; India 18\%, China $7 \%$, Pakistán 4\%, México 4\%, Tailandia 3\%, Colombia 3\%, y otros países representan el $27 \%$. Para la India, Pakistán y Turquía, representa la base fundamental de su economía. El liderazgo de Brasil en el mercado mundial actualmente se basa en los menores costos de producción y a la activa presencia del sector alcoholero como una importante alternativa de los subproductos de la caña en ese país. El crecimiento mundial de la Caña de Azúcar en el mundo fue 2\% entre los años 2000 y 2005, siendo Brasil el país que se mantuvo con el mismo nivel de producción.

En la costa y selva del Perú existen áreas aptas, en términos de calidad del suelo y condiciones climáticas, para el desarrollo de cultivos que provean los volúmenes de materia prima adecuada y a los precios necesarios para elaborar etanol a costos muy competitivos internacionalmente. En la costa se dispone de terrenos bajo explotación agrícola y otros aún no explotados, ambos dotados con infraestructura de riego. La di-

mensión de los mismos permitiría asegurar el suministro de la materia prima necesaria para producir el volumen anual de etanol para abastecer el mercado de gasolinas en el Perú.

En el ámbito de los proyectos de irrigaciones de Chinecas, Chavimochic, Tinajones, Jequetepeque-Zaña, Chira-Piura y Puyango-Tumbes, existen posibilidades para el cultivo de caña de azúcar. Estos proyectos de riego comprenden una extensión de, aproximadamente, 30 mil hectáreas de tierras disponibles; asimismo, están disponibles terrenos aún no explotados y para su entrega inmediata. Tal asignación es responsabilidad de PROINVERSION.

A lo anterior, debe agregarse la posibilidad de incorporar al proyecto de etanol terrenos agrícolas actualmente utilizados para cultivos poco o no rentables distintos a la caña de azúcar, así como terrenos agrícolas no explotados por razones económicas (costos de producción, carencia de financiamiento, precio-mercado, etc.). En las zonas mencionadas de la costa, se estima que existen alrededor de 200 mil Ha potencialmente disponibles para destinarse al cultivo de la caña de azúcar y/o del sorgo dulce; y en la selva existen más de un millón de hectáreas; además, existen posibilidades adicionales de sembrar cultivos energéticos en la selva y de esta manera contribuir a un Programa 


\section{Los biocombustibles y su efecto en la agricultura peruana}

de Desarrollo Alternativo Sostenible que genere un polo de desarrollo con todos los beneficios sociales que esto conlleva para el país.

A pesar de las grandes ventajas de uso de etanol para reducir las emisiones contaminantes de los vehículos gasolineros, el uso de etanol a nivel mundial se ha visto frenado por el mayor costo del etanol con relación a la gasolina convencional, por lo que en Brasil, EE.UU. y otros países se han establecido subsidios en diferentes modalidades a fin que ni el consumidor final ni el que prepara la mezcla con la gasolina vean afectadas sus economías. Se espera que el costo de producción de etanol en el Perú sea competitivo con los precios ex-Planta de los combustibles fósiles.

La búsqueda de materias primas para producir etanol con la finalidad de usarlo como combustible para vehículos debe estar orientada preferentemente hacia productos ricos en glucosa, maltosa y/o sacarosa, porque:

a. Estos azúcares son fermentados por todos los tipos de Saccharomices cereviceae (levaduras de panificación).

b. No se buscan características aromáticas ni de cuerpo especiales en el alcohol a obtener.

c. El trabajar con productos amiláceos (ricos en almidón) implica operaciones unitarias adicionales, como el trozado, molturación, dilución, acondicionamiento y una digestión (ácida o enzimática) hasta dextrinas (que no se fermentan), maltosa, sacarosa y glucosa, luego una decantación de las borras, un acondicionamiento del mosto y recién se podría empezar la fermentación alcohólica. Estas operaciones adicionales implican un costo, y se justificarían solo para productos a los que se quiera dar un valor agregado especial, mientras que en el presente caso, se trata de conseguir el alcohol al menor precio posible.

Una mención aparte merece la melaza, que es obtenida como subproducto de la industria azucarera y normalmente se destina a la alimentación de ganado. Partiendo de la melaza como materia prima se obviarían los costos de los tratamientos primarios, ya que solo se tendría que estandarizar antes de la fermentación. Si las mismas industrias azucareras se dedicaran a este rubro también se disminuirían los costos de transporte, lo que se debe traducir en un producto de menor precio. 


\section{Pedro Barrientos Felipa}

La agroindustria de etanol, basada en los cultivos de caña de azúcar y/o sorgo dulce, cuenta con la posibilidad de dos tipos de ingresos complementarios: por concepto de comercialización de subproductos y por reducción de emisiones de GEI. Estos ingresos complementarios son equivalentes, aproximadamente, al costo de producción principal, lo que le confiere una especial ventaja para afrontar la competencia. Bajo esas condiciones, es factible reducir precios de venta del producto principal sin generar un nivel negativo en el margen de operación que la actividad productiva debe observar.

La sustitución de gasolina por etanol anhidro implica reducir emisiones de GEI que incrementen el existente nivel de los mismos acumulado en la atmósfera. Por cada tonelada de gasolina que se deja de consumir se evita la emisión de 1,18 toneladas de Carbono. Los beneficios económicos al proyecto significarían, aproximadamente, 0,017 USD /litro de etanol como ingresos complementarios por MDL.

De acuerdo a los avances obtenidos, las alternativas viables estarían constituidas por las siguientes opciones (materias primas): caña de azúcar, sorgo dulce, yuca, residuos forestales y rastrojos de cultivos. Los dos primeros casos parecen ser los más alentadores. En el caso de la caña de azúcar, sus altos rendimientos le confieren al país un margen significativo para incursionar en la producción de etanol carburante. En los demás casos, sería necesario estudiar con mayor profundidad las condiciones de cultivo, tecnologías de proceso y localización.

Los ecologistas han hecho algunas objeciones a muchas prácticas agrícolas modernas, incluyendo algunas prácticas útiles para hacer el bioetanol más competitivo. Los efectos sobre los campos afectarían negativamente a la producción para consumo alimentario de la población.

\section{Biodiesel}

El Biodiesel es un combustible renovable derivado de aceites vegetales o grasas animales. Se define al Biodiesel como un derivado de insumos grasos renovables, como los aceites vegetales o grasas animales. El término bio hace referencia a su naturaleza renovable y biológica en contraste con el combustible diesel tradicional derivado del petróleo; mientras que diesel se refiere a su uso en motores de este tipo. 


\section{Los biocombustibles y su efecto en la agricultura peruana}

Sabemos que como combustible, el Biodiesel puede ser usado en forma pura o mezclado con diesel de petróleo. Una de sus fortalezas es que tiene una combustión más limpia, no malogra muchos los cilindros de los motores.

El biodiesel puede utilizarse de todas las prestaciones y de forma idéntica que el diesel oil, ya sea puro (al 100\%) o mezclado con este; aplicable tanto a motores de combustión interna (automotores, turbinas de gas, motores diesel, etc.) como en sistemas de combustión abierta (hornos, calderos, secadores, etc.); sin embargo, en la práctica mezclas con una participación mayor al $5 \%$ en volumen del biocombustible implica la necesidad de adaptaciones en los vehículos para evitar problemas en su desempeño. Pueden encontrarse otros usos:

- El biodiesel en estos tiempos se está utilizando con mayor frecuencia en la búsqueda de una alternativa de solución a los problemas energéticos actuales.

- Calefacción para el hogar en base a biodiesel. Mucha gente está apuntando sus ojos hacia el biodiesel como una alternativa para la calefacción del hogar. Muchas calderas a petróleo pueden funcionar bien con biodiesel (B20) que es un combustible fabricado con $80 \%$ de aceite de petróleo y un $20 \%$ de biodiesel.

- Hay quienes han reformado sus calderas para biodiesel (B100), un combustible realizado enteramente con aceites vegetales, y quema más limpio que el petróleo convencional.

- Generadores de electricidad en base a combustible biodiesel, es una alternativa superior al tradicional quemado de carbón de piedra. El biodiesel es más económico, limpio y renovable para generar electricidad.

- Camiones de transporte alimentados con biodiesel, poco a poco, más y más tractores de transporte de mercaderías cambian de diesel a biodiesel, los beneficios que obtienen son numerosos para no mencionar las ventajas de ayudar al medioambiente $y$ reducir la dependencia de petróleo extranjero, mientras se ahorra dinero.

- Maquinaria agrícola aprovecha el biodiesel que ayuda a producir, los tractores y las diferentes máquinas del campo, bombas de irrigación, generadores, sistemas de irrigación que habitualmente venían usando combustible diesel, ahora el uso de biodiesel para conseguir energía completa un círculo virtuoso en la agricultura desde productores a consumidores. 


\section{Pedro Barrientos Felipa}

- Embarcaciones de fletes comerciales como ferries, yates de paseo, botes de vela y de motor son todos candidatos a utilizar biodiesel. La empresa "Pacific Whale Foundation", localizada en Hawaii emplea el biodiesel en sus barcos.

- Aditivos lubricantes en base a biodiesel porque es un buen lubricante en comparación al de uso actual en base a petróleo poco sulfurado, los inyectores de combustible y otros tipos de bombas de combustible pueden perfectamente ser lubricados con biodiesel.

Solo se está considerando al biodiesel como sustituto parcial de la demanda de diesel en el Perú, que vendría a cubrir parte de las importaciones que realiza nuestro país. La producción de biodiesel es mínima en el país, puesto que este mercado aún no se ha desarrollado dentro de nuestras fronteras. Sin embargo, sería favorable producir biodiesel por dos razones principalmente: (i) El parque automotor de transporte pesado $y$ de pasajeros es mayoritariamente a diesel; $y$, (ii) se produce con un sinnúmero de productos agrícolas, deshechos agrícolas y aceite reciclado.

En estos años de cambio energético mundial, dadas las perspectivas de agotamiento y escalada del precio mundial del petróleo, el mercado mundial de recursos energéticos se aproxima a una situación crítica, la demanda mundial futura no será satisfecha dado que el consumo en los próximos años excederá a los recursos energéticos prevalecientes. La Unión Europea es el principal productor y a la vez consumidor de biodiesel, buscando un incremento en el uso de energías renovables, diversificación de fuentes de energía entre otros objetivos a largo plazo.

La producción de biodiesel en el mundo se ha incrementado notablemente, siendo Alemania el principal productor de este biocombustible seguido por países como Francia, Estados Unidos, Italia y Austria. La producción de este biocombustible ha tenido un crecimiento espectacular en los últimos años; por ejemplo, podemos mencionar que entre los años 2000 y 2005, esta se ha cuadruplicado, todo ello generando gracias al incremento que se esta dando es estos momentos y como proyecto a futuro de las inversiones en instalaciones propias para el desarrollo de estos biocombustibles y en especial del biodiesel en el cual la Unión Europea, encabezada por Alemania, son los principales inversionistas que apuestan por este recurso, el cual estaría destinado para un bien sustituto al diesel convencional. 


\section{Los biocombustibles y su efecto en la agricultura peruana}

Cuadro N. ${ }^{\circ}$ 3. Principales productores de biodiesel en el mundo.

\begin{tabular}{|c|c|c|c|c|}
\hline País & Año & $\begin{array}{c}\text { Producción } \\
\text { (Millones litros/ } \\
\text { año) }\end{array}$ & Insumos utilizados & Tipo de uso \\
\hline Alemania & 2005 & 1.920 & $\begin{array}{l}\text { Colza, girasol, y/o aceite de } \\
\text { cocina reciclado }\end{array}$ & $\begin{array}{l}\text { Uso puro en todo tipo de } \\
\text { vehículos. }\end{array}$ \\
\hline Francia & 2005 & 511 & $\begin{array}{l}\text { Colza, girasol, y/o aceite de } \\
\text { cocina reciclado }\end{array}$ & \\
\hline $\begin{array}{l}\text { Estados } \\
\text { Unidos }\end{array}$ & 2005 & 290 & $\begin{array}{l}\text { Más del } 90 \% \text { proviene de } \\
\text { soya, el resto de grasa } \\
\text { amarilla, otros aceites o } \\
\text { grasas animales }\end{array}$ & $\begin{array}{l}\text { B100, B20 y B2, principalmente } \\
\text { en flotas cautivas, pero también } \\
\text { venta al publico de y uso en } \\
\text { minas subterráneas (por motivos } \\
\text { de salud ocupacional). }\end{array}$ \\
\hline Italia & 2005 & 227 & $\begin{array}{l}\text { Girasol y/o aceite de cocina } \\
\text { reciclado }\end{array}$ & $\begin{array}{l}90 \% \text { del biodiesel se usa puro } \\
\text { o mezclado con } 20 \% \text { de diesel } \\
\text { fósil, para usos térmicos como } \\
\text { calefacción. Inicios en usos para } \\
\text { el transporte especialmente } \\
\text { flotas cautivas. }\end{array}$ \\
\hline China & 2004 & 138 & $\begin{array}{l}\text { Colza, semilla de algodón, } \\
\text { aceite de cocina reciclado. }\end{array}$ & $\begin{array}{l}\text { Exportado a Hong Kong; de uso } \\
\text { principal en flotas cautivas }\end{array}$ \\
\hline $\begin{array}{l}\text { República } \\
\text { Checa }\end{array}$ & 2002 & 63 & $\begin{array}{l}\text { Colza, girasol, y/o aceite de } \\
\text { cocina reciclado }\end{array}$ & $\begin{array}{l}\text { Mezcla de diésel con } 30 \% \text { a } \\
40 \% \text { de biodiesel. }\end{array}$ \\
\hline Australia & 2004 & 36 & $\begin{array}{l}\text { Aceite de cocina reciclado, } \\
\text { grasas animales }\end{array}$ & \\
\hline Austria & 2005 & 30 & $\begin{array}{l}\text { Colza y/o aceite de cocina } \\
\text { reciclado }\end{array}$ & $\begin{array}{l}\text { Mezcla de biodiesel de colza } \\
\text { con diésel, o biodiesel puro de } \\
\text { aceite de fritura. }\end{array}$ \\
\hline España & 2002 & 7 & $\begin{array}{l}\text { Girasol, aceite de cocina } \\
\text { reciclado }\end{array}$ & Flotas cautivas. \\
\hline $\begin{array}{l}\text { Reino } \\
\text { Unido }\end{array}$ & 2002 & 5 & $\begin{array}{l}\text { Principalmente aceite de } \\
\text { cocina reciclado, también } \\
\text { colza. }\end{array}$ & $\begin{array}{l}\text { Venta directa a flotas o en } \\
\text { algunas estaciones de servicio. } \\
\text { Promoción del B5. }\end{array}$ \\
\hline Suecia & 2002 & 3 & Colza. & Flotas cautivas. \\
\hline Suiza & 2002 & 1 & Principalmente colza. & $\begin{array}{l}\text { Uso en cooperativas agrícolas y } \\
\text { como B100 en pocas estaciones } \\
\text { de servicio. }\end{array}$ \\
\hline
\end{tabular}

Fuentes: F.O. Licht's World Ethanol \& Biofuels Report (2005), Friedrich (2004), Austrian Biofuels Institute (citado por Friedrich, 2004). 


\section{Pedro Barrientos Felipa}

El incremento en el uso de la biomasa podría producir las siguientes ventajas en los próximos años:

- Diversificación del uso de suministro de energía en Europa, incrementando la cuota de la energía de fuentes renovables en un 5\% y reduciendo la dependencia de la energía importada de $48 \%$ a $24 \%$.

- Reducción de las emisiones de gases de efecto invernadero de 209 millones de toneladas de $\mathrm{CO} 2$ al año.

- Empleo directo para 250000 - 300000 personas, sobre todo en zonas rurales.

- La posible presión a la baja en el precio del petróleo como consecuencia de la menor demanda de crudo.

- Palanca de desarrollo del agro peruano.

- El biodiesel no contiene productos orgánicos aromáticos (benceno y derivados) que son sustancias cancerígenas.

- Al tener un punto de inflamación superior al diesel, su transporte es más seguro.

- No contamina los suelos y aguas subterráneas en caso de derrame accidental. Es biodegradable y en 28 días desaparece todo rastro de contaminación en caso de derrame.

- Los proyectos agro industriales que generen biodiesel tendrán como incentivos los bonos MDL.

- Se presenta como una oportunidad para reemplazar progresivamente parte de la importación de diesel, y reducir la contaminación ambiental, generando al mismo tiempo nuevas oportunidades de desarrollo agrícola y agroindustrial en el país.

Existen diversos productos agrícolas que pueden ser utilizados como materia prima para obtener biodiesel, las ventajas competitivas de los mismos depende de la tierra, el clima y el agua de que se disponga. Son las decisiones que se tomen respecto a esos cultivos los que afectarán a la agricultura local, en diversos aspectos, que no solo incluyen producción.

- Palma aceitera. Teóricamente las áreas potenciales superan el millón de Has. Exigente en factores ecológicos y manejo de cultivo adecuado, la industria debe acompañar al cultivo. Excelente complemento con la industria de Biodiesel. 


\section{Los biocombustibles y su efecto en la agricultura peruana}

- Piñon. Ideal para zonas depredadas, marginales, cultivo muy rústico y altamente productivo en aceites. Uso múltiple-ideal para biodiesel. Limitante para su desarrollo es el alto costo de mano de obra por cosecha manual. Es necesaria la investigación adaptativa, varietal y de manejo.

- Higuerilla o Ricino. Se complementa con el Piñón y otros cultivos asociados, cultivo rústico adaptado a diferentes tipos de suelo incluido marginales y depredados por la actividad agrícola y cocalera.

- Mani. Cultivo casi originario del Perú, ancestral y de gran adaptación. Requiere suelos sueltos, de buena fertilidad y drenaje. Siendo limitante el manejo especial que requiere. Muchos trabajos de investigación desarrollados en los últimos años demuestran su gran capacidad de rendimiento para aceite y biodiesel.

- Soya o Soja. Leguminosa adaptada a condiciones cálidas en especial las tropicales, exigente en suelos, intensivo requiere maquinaria desde preparación a cosecha. Ideal para rotación de cultivos anuales. Buen mercado de aceites y torta. Es rentable en grandes extensiones. EE.UU. y Argentina la utilizan como insumo de biodiesel. Hay variedades de alto rendimiento sin ser transgénicas.

- Girasol. Cultivo intensivo, rentable si se siembra en grandes extensiones y es totalmente mecanizado. Se adapta extraordinariamente en zona de Selva, cultivada desde tiempos inmemoriales. La existencia de híbridos de alto rendimiento favorecen su desarrollo. Productor de aceite, torta y forraje.

- Sacha Inchi. Cultivo oleaginoso de gran demanda por la riqueza de su aceite, rico en omega 3. Se está trabajando en la selección de cultivares con tolerancia a problemas sanitarios, en especial nematodos, así como en las técnicas de manejo de cultivo, Por la dificultad y alto costo de instalación es ideal para pequeñas extensiones. Su alto costo no permitirá su uso como Biodiesel.

- Colza o Canola. El cultivo de la canola se desarrolla a partir de los $400 \mathrm{~mm}$ de lluvia, resiste sequía invernal y sufre con inundaciones. En floración no es conveniente que se encuentre expuesto a temperaturas altas para no acortar su ciclo y logre granazón.

\section{El caso de la palma aceitera}

Si bien es cierto que no hay una respuesta única y contundente en cuanto a qué insumo es el más indicado para la producción de biodiesel, ya que el cultivo a recomendar 


\section{Pedro Barrientos Felipa}

dependerá de la zona, clima, tierra y agua; nos hemos basado en un ejercicio de proyección que incluye toda la información disponible actual. Sin embargo, podemos decir que la palma aceitera es el insumo más rentable para la producción de biodiesel en el Perú. Se presenta como una oportunidad para reemplazar progresivamente parte de la importación de diesel, y reducir la contaminación ambiental, generando al mismo tiempo nuevas oportunidades de desarrollo agrícola y agroindustrial en el país. El biodiesel es importante no solo porque constituye un elemento o palanca de desarrollo del agro peruano a través del desarrollo de cientos de empresas agroindustriales, sino además un elemento importante para descontaminar las principales ciudades del país.

El principal cultivo oleaginoso en el Perú es la Palma aceitera, que se produce principalmente en la región amazónica, y tendría aún un amplio potencial de crecimiento. Según cifras oficiales, la superficie instalada con plantaciones de palma aceitera en el Perú asciende a $21.200 \mathrm{Ha}$, de las cuales alrededor del $60 \%$ (12.400 Ha) se encuentran en producción (ver Tabla 3.7). La productividad de estas plantaciones tiene una gran variación según el nivel de tecnología que se emplee.

Su rendimiento se encuentra en un rango entre 1,7 y 5,7 toneladas de aceite crudo por hectárea (Sáenz, 2005). Se estima que habría alrededor de 32 mil productores de palma, ubicados en diferentes zonas de Loreto, San Martín, Huánuco y Ucayali, quienes se encuentran organizados en la Confederación Nacional de Palmicultores y Empresas de Palma Aceitera (CONAPAL). Existen además, cuatro plantas extractoras de aceite, ubicadas en Pucallpa, Aguaytía y Tocache, cuya capacidad se encuentra subutilizada en la actualidad. Se requeriría ampliar las áreas de cultivo de palma hasta unas 70 mil hectáreas con el fin de satisfacer la demanda de estas plantas (CEPES, 2004).

Cuadro N. ${ }^{\circ}$ 4. Producción actual de palma aceitera en el Perú.

\begin{tabular}{lrrrrrrr}
\hline Región & $\begin{array}{c}\text { Área en } \\
\text { producción } \\
\text { (ha) }\end{array}$ & $\begin{array}{c}\text { Área de } \\
\text { crecimiento } \\
\text { (ha) }\end{array}$ & $\begin{array}{c}\text { Área de } \\
\text { vivero (ha) }\end{array}$ & $\begin{array}{c}\text { Área por } \\
\text { rehabilitar } \\
\text { (ha) }\end{array}$ & $\begin{array}{c}\text { Área total } \\
\text { (ha) }\end{array}$ & $\begin{array}{r}\text { Producción } \\
\text { de racimos } \\
\text { (TYM) }\end{array}$ & $\begin{array}{c}\text { Producción } \\
\text { de aceite } \\
\text { crudo (TM) }\end{array}$ \\
\hline San Martín & 9.800 & 2.570 & 1.320 & 0 & 13.690 & 180.000 & 39.600 \\
Ucayali & 2.537 & 1.895 & 1.500 & 0 & 5.932 & 36.592 & 8.050 \\
Loreto & 100 & 500 & 500 & 300 & 1.400 & 1.200 & 264 \\
Huánuco & 0 & 0 & 200 & 0 & 200 & 0 & 0 \\
TOTAL & 12.437 & 4.965 & 3.520 & 300 & 21.222 & 217.792 & 47.914 \\
\hline
\end{tabular}

Fuente: Direcciones Regionales Agrarias de San Martín, Ucayali, Loreto y Huánuco. 


\section{Los biocombustibles y su efecto en la agricultura peruana}

Según estudios realizados por el Ministerio de Agricultura realizados en el año 1999, se descubrieron alrededor de 1405000 hectáreas listas para su potencial uso, el estudio mostró que alrededor del $44.13 \%$ de Ha se encuentran en las diferentes zonas de Loreto, así como también hay grandes hectáreas en Amazonas, Ucayali y San Martín mostrando a la selva como una zona privilegiada para la producción de Palma aceitera.

Cuadro N. ${ }^{\circ}$ 5. Áreas potenciales de palma aceitera - Perú 1999.

\begin{tabular}{llr}
\hline \multicolumn{1}{c}{ Departamento } & \multicolumn{1}{c}{ Zona } & Hectáreas \\
\hline Amazonas & Condorcanqui & 300.000 \\
Cusco & Bajo Urubamba & 30.000 \\
Huánuco & Tomavista & 15.000 \\
Huánuco & Pachitea & 40.000 \\
Huánuco - Ucayali & Honoria - Iparia & 50.000 \\
Loreto & Pastaza - Tigre & 180.000 \\
Loreto & Ramón Castilla & 140.000 \\
Loreto & Manití & 300.000 \\
San Martín & Tocache - Juanjui & 100.000 \\
San Martín & Cainaracha - Barranquita & 50.000 \\
Ucayali & Padre Abad & 100.000 \\
Ucayali & Atalaya & 100.000 \\
& Total & 1405.000 \\
\hline
\end{tabular}

Fuente: Ministerio de Agricultura

La productividad de estas plantaciones tiene una gran variación según el nivel de tecnología que se emplee; sin embargo, se puede decir que su rendimiento se encuentra en un rango entre 1,7 y 5,7 toneladas de aceite crudo por hectárea. Un factor es el rendimiento en la producción del Biodiesel, es decir, la eficiencia del proceso de transformación del aceite en biodiesel, otro factor igualmente importante es el precio de los aceites, materia prima para producir el biocombustible.

Menor importancia tienen el precio de la glicerina subproducto del proceso; los costos de inversión en la planta de producción; el precio del metanol, insumo del proceso; el costo de operación (mano de obra); el costo del catalizador, otro insumo menor; y el costo de la energía requerida para el proceso de transformación. 


\section{Pedro Barrientos Felipa}

El principal cultivo oleaginoso en el Perú es la palma aceitera, que se produce principalmente en la región amazónica debido a que cuenta con condiciones edafoclimáticas favorables para su cultivo, y tendría aún un amplio potencial de crecimiento. Según cifras oficiales, la superficie instalada con plantaciones de palma aceitera en el Perú asciende a 21200 Ha; de las cuales, alrededor del 60\% (12 $400 \mathrm{Ha}$ ) se encuentra en producción. El mercado favorece la expansión de los cultivos oleaginosos para la producción de biodiesel en zonas tropicales. Los cultivos de zonas tropicales rinden más por hectárea, y tanto la tierra como la mano de obra son más baratas, por lo que el aceite resultante es también más barato que el producido en zonas templadas.

Se estima que habría alrededor de 32 mil productores de palma, ubicados en diferentes zonas de Loreto, San Martín, Huánuco y Ucayali, quienes se encuentran organizados en la Confederación Nacional de Palmicultores y Empresas de Palma Aceitera (CONAPAL). Existen, además, cuatro plantas extractoras de aceite, ubicadas en Pucallpa, Aguaytía y Tocache, cuya capacidad se encuentra subutilizada en la actualidad. Se requeriría ampliar las áreas de cultivo de palma hasta unas $70000 \mathrm{Ha}$ con el fin de satisfacer la demanda de estas plantas.

Al realizar un análisis de cultivos y ver su viabilidad La principal ventaja la tiene la caña de azúcar, por el alto rendimiento que este insumo presenta. Sin embargo, tiene una ligera desventaja en el consumo medio de agua, pero este es insignificante. La palma aceitera también presenta altos rendimientos, sobretodo en la amazonía de nuestro país; por ello, la palma aceitera es el insumo más rentable si lo que se desea es la producción de biodiesel; así como la caña de azúcar es el insumo más rentable en la producción de etanol.

\section{Mercado de Bonos de Carbono}

"Mercado de Carbono" es un conjunto de transacciones en el que se intercambian cantidades de reducciones de emisiones de gases de efecto invernadero. Podemos distinguir dos grandes esferas en las que se realizan las transacciones de carbono: en una se desarrollan las transacciones de carbono que buscan cumplir con el marco establecido por el Protocolo de Kyoto, y, en la otra, iniciativas paralelas de comercio de emisiones 


\section{Los biocombustibles y su efecto en la agricultura peruana}

fuera del Protocolo, como las iniciativas voluntarias de restricción de emisiones y las decisiones federales y estatales de los Estados Unidos para mitigar Gases de Efecto Invernadero (GEI), país que no es parte del Protocolo de Kyoto.

La institución pionera en el Mercado de Carbono de Kyoto es la iniciativa del Banco Mundial, el Fondo Prototipo de Carbono (Prototype Carbon Fund - PCF, por sus siglas en inglés), lanzado en el año 2000 con el fin de catalizar el mercado de emisiones reducidas basado en proyectos bajo los mecanismos de IC y Modelos de Desarrollo Limpio (MDL) del Protocolo de Kyoto. El Banco Mundial en conjunto capitaliza cerca de 600 millones de dólares, lo que lo convierte en el principal comprador del mundo

El PCF administra 180 millones de dólares, que ya están comprometidos en su cartera de proyectos. Nuevos fondos administrados por el Banco Mundial intentan consolidar el mercado de carbono: el Fondo de Carbono para el Desarrollo Comunitario (CDCF, por sus siglas en inglés) busca impulsar el mercado de proyectos de pequeña escala; el Fondo Holandés para el MDL (NCDF, por sus siglas en inglés), financiado por el Gobierno de ese país, el Fondo de Carbono Italiano y el Fondo Español adquiere solo reducciones de emisiones provenientes de proyectos MDL

La CAF, con el apoyo del Centro para el Desarrollo Sostenible en las Américas (CSDA), estableció, en mayo de 1999, el Programa Latinoamericano del Carbono (PLAC). La CAF suscribió un acuerdo con el Gobierno Holandés para establecer el "CAF-Netherlands CDM Facility" con el fin de adquirir reducciones de emisiones de GEI. Este acuerdo facilitará la transacción de hasta 10 millones de toneladas de reducciones de GEI en los próximos tres años.

\section{CONCLUSIONES Y RECOMENDACIONES}

El Perú cuenta con las suficientes condiciones necesarias para producir etanol de manera rentable, debido a que la caña de azúcar (insumo) cuenta una mayor productividad que la del promedio del resto del mundo. Estas ventajas son transmitidas al costo (el 60\% depende del insumo), el cual es menor por litro producido; es decir, se cuenta con una ventaja comparativa en la producción de etanol. 


\section{Pedro Barrientos Felipa}

La costa norte es la región que muestra las mejores oportunidades para producir etanol, no solo por tener amplias extensiones de tierras agrícolas, las cuales pueden ser sometidas a regímenes de riego, sino también por la puesta de nuevos y ambiciosos proyectos que han hecho aumentar la rentabilidad en sus tierras (más de una cosecha al año) atrayendo nuevas inversiones a una industria como la cañera que comienza a tener excesos de producción que pueden ser dirigidos a la producción de los biocombustibles.

La alta volatilidad del precio del petróleo, el daño climático causado por su uso y el proceso de reemplazo de las matrices energéticas en EE.UU. y la Unión Europea aseguran una demanda externa creciente y sostenida para el futuro. Por otro lado, la demanda interna está siendo fomentada por la ley de promoción de los biocombustibles. Es así que la demanda de biocombustibles a nivel mundial estaría asegurada de cumplirse este panorama.

Habría algunas industrias afectadas por la sustitución de terrenos para la producción de las materias primas necesarias como la alimenticia, y al mismo tiempo otras favorecidas por el menor costo de los combustibles. Sin embargo, el Estado, ya sea a través de los ministerios o de los gobiernos regionales, deberá prepararse para afrontar las posibles dificultades en su desarrollo, así como para verse favorecido con sus logros. El papel del Estado es primordial para brindar las condiciones necesarias para la expansión de esta industria emergente, es decir, fomentar a la inversión, un marco legal favorable y una mayor apertura de nuestros mercados (TLC).

El etanol puede ser utilizado en los vehículos de combustión interna que conforman el parque automotor existente. Para ello, no es necesario realizar modificaciones sustantivas en los motores de explosión convencionales. En efecto, para el caso de los vehículos a gasolina puede usarse etanol anhidro hasta un $10 \%$ en mezcla con gasolina sin necesidad de adaptaciones en el motor. El uso de gasolina/etanol anhidro en proporciones de hasta 75/25 en motores de combustión convencionales, requiere de adaptaciones/modificaciones menores (por ejemplo incorporación de piezas niqueladas en los sistemas de carburación/inyección, cambio de algunas empaquetaduras y ajustes en el sistema de ignición). 


\section{Los biocombustibles y su efecto en la agricultura peruana}

\section{BIBLIOGRAFÍA}

\section{Libros}

Czinkota, Michael; Ronkainen, Ilkka; Moffet, Michael. "Negocios Internacionales" 7. ma ed., International Thomson Editores S. A. de C. V., México D. F., 2007

Ohmae, Kenichi. El próximo escenario global. España S. A. U. Madrid, McGraw-Hill Interamericana, 2008.

\section{Páginas web}

Agencia de Promoción de la Inversión Privada - PROINVERSION: www.proinversion. gob.pe

Consejo Nacional del Ambiente: www.conam.gob.pe

Programa Sierra Exportadora: www.sierraexportadora.gob.pe 